Original Research

\title{
The Spatiotemporal Characteristic of Carbon Emissions from China's Power Sector and its Determinants: A Spatial Econometric Analysis
}

\author{
Xiping Wang*, Moyang Li \\ Department of Economics and Management, North China Electric Power University, Baoding, China
}

Received: 8 May 2018

Accepted: 4 September 2018

\begin{abstract}
Based on the estimation of carbon emissions (CE) from the power sector throughout China's 30 administrative regions in the period of 2003 to 2013, this study investigated the space-time evolution characteristic and its determinants using spatial autocorrelation test and the spatial Durbin model (SDM). The main results are as follows: (1) The CE from power sector increased from 1.58 billion tons to 3.88 billion tons, with an average annual growth rate of $9.54 \%$, while obvious imbalance existed among different regions. (2) According to spatial analysis, the global Moran's I values of CE from the power sector are significantly positive during the sample period, meaning that the CE has an obvious clustering effect. The local spatial autocorrelation index confirms the imbalance of spatial distribution of the power sector's CE. (3) Results of the spatial Durbin model show that the urbanization rate, per capita GDP, and fee-based environmental regulations have a spatial spillover effect. Based on the above findings, several policy suggestions are presented in this article.
\end{abstract}

Keywords: carbon emissions from the power sector, spatial Durbin model, space-time evolution

\section{Introduction}

In response to climate change, low-carbon development has become the consensus of all countries around the world. China, as the world's largest $\mathrm{CE}$ contributor, has proposed both intensity targets $^{1}$ and total amount target of CE reduction. Early in 2009, the State Council announced that China would reduce its carbon intensity by $40-45 \%$ by 2020 from 2005 levels. [1-4]. In 2015, China signed the Paris Agreement with 125 other countries and set an even more ambitious target of reducing emissions by $60-65 \%$ by 2030 compared to 2005 levels and peaking its CE by around 2030. [5] The power industry is of vital importance for achieving the

Here, carbon intensity refers to $\mathrm{CO}_{2}$ emissions per unit of GDP. 
above targets, since it consumes approximately $50 \%$ of China's coal and emits more than $40 \%$ of China's $\mathrm{CO}_{2}$ from fossil fuel combustion [6] - more than any other sector. And this pattern is unlikely to be changed in the near future considering China's energy structure, which is characterized by abundant coal and relatively scarce oil and gas resources. Thus, analyzing the space-time evolution characteristic of CE and its determinants is of great importance not only for the power industry's lowcarbon transition and sustainable development, but also for achieving the national $\mathrm{CE}$ reduction targets.

In the literature, various methodologies have been utilized to explore the driving factors of $\mathrm{CE}$ from the electricity sector, which can be classified into two categories: decomposition analysis and econometric analysis. Nowadays, both the structural decomposition analysis (SDA) and index decomposition analysis (IDA) have been widely applied to analyze the impact of different factors on the change of energy-related CE. [7] Specifically, log mean divisia index (LMDI), as one of the index decomposition approaches, has gained popularity because of its robust theoretical foundations, strong adaptability, and perfect decomposition, without unexplained residual terms in the results. [8, 9] LMDI has also been widely applied to study the influencing factors of $\mathrm{CE}$ from power generation, examples such as [10-12]

Decomposition analysis provides a good analytical framework for analyzing CE from the power sector. However, some important influencing factors, including urbanization, environmental regulation, and so on, cannot be included in the decomposition. To solve this problem, econometric analysis has been paid much attention. Based on the STIRPAT model, Li et al. (2011) [13] found that China's $\mathrm{CO}_{2}$ emissions are determined by economic growth, industrial structure, population size, and the urbanization and technical levels. Similarly, Yan et al. (2010) [14] found that it is most beneficial to Shanghai's $\mathrm{CO}_{2}$ emission reduction when population and economy maintain moderate speed development, urbanization slows down and energy savings and emission reduction technologies make great progress. Moreover, Zhu et al. (2010) [15] showed that the factors influencing the change of total CE in China are urbanization rate, population size and residents' consumption level.

A possible shortcoming of the above studies is that they are based on independence assumption and ignore the spatial interaction effects. [16] According to Tobler's first law of geography [17], all attribute values on a geographic surface are related to each other. Thus, it is necessary to take the spatial effects into account when we study the issue of $\mathrm{CO}_{2}$ emissions. In addition, since the power sector is the largest source of $\mathrm{CO}_{2}$ emissions, it is important and necessary to study the spatiotemporal characteristics of $\mathrm{CE}$ from the power sector and its determinants. Compared with previous studies, the contributions of this study are as follows. First, the spatial correlation of CE from the power sector was examined based on the global Moran's I index and local Moran's I index, gaining deeper insight into the cluster pattern of CE in space. Second, an SDM model was estimated to analyze the spatial spillover effects of the determinants on $\mathrm{CE}$ from the power sector. The rest of this paper is organized as follows. After introduction, section 2 introduces the methods and data used in this study. Section 3 presents the empirical results and analyses. Finally, in section 4 we summarize the study and provide some suggestions.

\section{Material and Methods}

Global spatial autocorrelation: to test the global spatial autocorrelation of China's provincial power $\mathrm{CE}$, the global Moran's I index is employed, as shown in Eq. (1):

$$
\begin{gathered}
I=\frac{\sum_{i=1}^{\mathrm{n}} \sum_{\mathrm{j}=1}^{n} W_{i j}\left(C E_{i}-\overline{C E}\right)\left(C E_{j}-\overline{C E}\right)}{\sigma^{2} \sum_{i=1}^{n} \sum_{j=1}^{n} W_{i j}} \\
\overline{C E}=\frac{1}{n} \sum_{i=1}^{n} C E_{i} \quad \sigma^{2}=\frac{1}{\mathrm{n}} \sum_{i=1}^{n}\left(C E_{i}-\overline{C E}\right)
\end{gathered}
$$

...where $\mathrm{CE}_{\mathrm{i}}$ and $\mathrm{CE}_{\mathrm{j}}$ represent the $\mathrm{CE}$ from power generation of provinces $i$ and $j$ respectively; $n$ is the number of provinces, and $\mathrm{W}_{i j}$ stands for the spatial weight matrix, which describes the spatial adjacent relations between each province. The value of global Moran's I index ranges from -1 to 1 . When it lies in the range of $(-1,0]$, the spatial distribution of $\mathrm{CE}$ is negatively correlated, and the closer to -1 the value is, the stronger the negative correlation is. When the value of Moran's I is in the range of $(0,1]$, the spatial distribution of $\mathrm{CE}$ is positively correlated, and the closer to 1 the value is, the stronger the positive correlation is. If the value equals 0 , there is no spatial dependence and the power CE exhibits a random spatial distribution.

Local spatial autocorrelation: in order to further investigate the contribution of a specific province to Moran's I, the local spatial correlation index is introduced, specified as Eq. (2):

$$
I_{i}=\left(\mathrm{C} E_{i}-\overline{C E}\right) \sum_{i=1}^{n} W_{i j} / \sum_{i=1}^{n}\left(\mathrm{C} E_{i}-\overline{C E}\right)^{2}
$$

...where $I_{i}$ is the local spatial autocorrelation index. Index $I_{i}$ describes the spatial clustering degree of $\mathrm{CE}$ of each province with its neighbors in a certain period. If $I_{i}>0$, it represents the $\mathrm{HH}$ or LL clustering, meaning that province $i$ has similar CE in electricity generation to its neighboring provinces. However, If $I_{i}<0$, it implies HL or LH clustering, which means that province $i$ is contiguous to neighboring provinces with different CE. 
Spatial econometric models. Generally speaking, three kinds of spatial econometric models are obtained: spatial lag model (SLM), spatial error model (SEM) and SDM. SLM is applied to a situation where the economic activity of a local region is affected by the economic activities of neighboring regions because of the spillover effects. SEM, containing interaction effects among the error terms, is applied to a situation where the regional interaction effects are caused by the omitted variables. SDM is a combination of the former two models that includes both endogenous interaction effects among the dependent variable and interaction effects among the error terms. The three models are specified as Eqs. (3-5):

$$
\begin{gathered}
C E_{i t}=\delta \sum_{j=1}^{n} w_{i j} C E_{j t}+\beta x_{i t}+\mu_{i}+\lambda_{t}+\varepsilon_{i t} \\
\varepsilon_{i t} \sim i . i . d\left(0, \delta^{2}\right) \\
C E_{i t}=\beta x_{i t}+\mu_{i}+\lambda_{t}+\varphi_{i t} \quad \phi_{i t}=\rho \sum_{j=1}^{n} \mathrm{w}_{i t} \phi_{j t}+\varepsilon_{i t} \\
C E_{i t}=\delta \sum_{j=1}^{n} w_{i j} C E_{j t}+\beta x_{i t}+\sum_{j=1}^{n} w_{i t} x_{i j t} \theta+\mu_{i}+\lambda_{t}+\varepsilon_{i t}
\end{gathered}
$$

...where $\mathrm{CE}$ is an $\mathrm{n} \times 1$ vector of the dependent variable, $x$ denotes an $\mathrm{n} \times \mathrm{k}$ matrix of observations; $\beta$ is an associated $\mathrm{k} \times 1$ vector with unknown parameters to be estimated, which reflects the influence of the explanatory variables on $\mathrm{CE}$; $w \mathrm{CE}$ denotes the endogenous interaction effects among CE; $\varphi$ and $w \varphi$ denote a vector of error terms and the interaction effects among the error terms; $\delta$ is the spatial autoregressive coefficient; and $\rho$ denotes the spatial autocorrelation coefficient on the error terms. $\mu_{i}$ and $\lambda_{t}$ stand for spatial fixed effects and time fixed effects, respectively. $\varepsilon$ is a vector of disturbance terms that are independent and identically distributed normal random variables.

Since the estimation of the spatial panel model cannot be described as the marginal effect of the independent variable on $\mathrm{CE}$, the partial differential equation is used to test the direct effect and spillover effect of the variable, as shown in Eq. (6):

$$
\begin{gathered}
{\left[\frac{\partial C E}{\partial X_{1 k}} \cdot \frac{\partial C E}{\partial X_{N k}}\right]_{t}=\left[\begin{array}{ccc}
\frac{\partial C E_{1}}{\partial X_{1 k}} & \cdots & \frac{\partial C E_{1}}{\partial X_{N k}} \\
\cdot & \cdots & \cdot \\
\frac{\partial C E_{N}}{\partial X_{1 k}} & \cdots & \frac{\partial C E_{N}}{\partial X_{1 k}}
\end{array}\right]_{t}} \\
(I-\delta W)^{-1}\left[\begin{array}{cccc}
\beta_{k} & w_{12} \lambda_{k} & \cdots & w_{1 N} \lambda_{k} \\
w_{21} \lambda_{k} & \beta_{k} & \cdots & w_{2 N} \lambda_{k} \\
\cdot & \cdot & \cdots & \cdot \\
w_{N 1} \lambda_{k} & w_{N 2} \lambda_{k} & \cdots & \beta_{k}
\end{array}\right]_{t}
\end{gathered}
$$

...where $\mathrm{I}_{n}$ is an n-dimensional identity matrix. The indirect effect of province $j$ on province $i$ can be interpreted as the average indirect effect of a change across all provinces $j$ on $\mathrm{CE}_{i}$. Spatial spillovers are measured in this analysis using an indirect effect. The coefficient $\beta_{k}$ can be interpreted as the direct effect of a change in variable $\mathrm{k}$ in province $i$ on $\mathrm{CE}_{i}$. Finally, the total effect of a change in variable $\mathrm{k}$ on $\mathrm{CE}_{i}$ is measured by the $i^{\text {th }}$ row entry in Eq. (6) [18].

\section{Data and Variable}

Considering data's availability and integrity, this study takes power sectors in China's 30 provincial administrative regions (except Tibet, Hong Kong, Macao and Taiwan) from the year 2003 to 2013 as the analysis sample. Since the official data on CE from regional power generation are not available in China, we use formula (7), which follows the IPCC [19] guidelines, to calculate $\mathrm{CE}$ from electricity generation in province $i$.

$$
C E_{i}=E_{i m} \cdot S_{i m} \cdot \xi_{i m} \cdot \eta_{i m} \cdot 44 / 12
$$

...where $m$ is the category of energy ${ }^{2}$; E denotes the quantity of consumption of a certain energy product; $S$ refers to the net calorific value of a certain energy product; $\xi$ stands for the $\mathrm{CE}$ coefficients, $\eta$ represents the carbon oxidation factor, and 44 and 12 are the molecular weights of $\mathrm{CO}_{2}$ and carbon, respectively.

Referring to existing studies [20-22], the following variables are selected as the driving factors.

Urbanization rate (UR): as an important indicator to reflect population structure, urbanization is closely related to industrialization and electricity consumption. UR is represented by the proportion of urban population to the total population and the expected symbol is positive.

Per-capita GDP (P-GDP): the environmental Kuznets curve (EKC) indicates that economic growth plays an important role in $\mathrm{CO}_{2}$ emissions [23]. Several previous studies have found that economic activity was the major factor responsible for the increase of emissions. This study takes per-capita GDP as the proxy of economic growth.

Electricity generation structure (ES): represented by the proportion of thermal power production. Similar to previous studies, this study assumes that power CE mainly comes from thermal power generation. Thus, a higher ES generally corresponds to a higher $\mathrm{CO}_{2}$ emission, and the expected symbol is positive.

\footnotetext{
This study specifically selected 23 kinds of power production consume energy to ensure the accurate calculation of power CEs. The 23 kinds of energy include: raw coal, washed coal, other coal washing, briquette, gangue, coke, coke oven gas, blast furnace gas, converter gas, other coal gas, other coking products, crude oil, gasoline, diesel, fuel oil, petroleum coke, liquefied petroleum gas, dry gas from refineries, other petroleum products, natural gas, liquefied natural gas, heat and other energy sources.
} 
Standard coal consumption (MH): an index reflects the power generation technology of power plants. A lower $\mathrm{MH}$ per electricity output means less energy needed to generate the same electricity. Conversely, CE will be increased. The expected sign is positive.

Environmental regulation: several studies [2425] have investigated the impact of environmental regulation on China's thermal power performance. In this study, the regulations are further divided into two different categories, i.e., the investment-based environmental regulations (EVIN) and fee-based environmental regulations (FEE). They are represented by the investment in the treatment of industrial pollution and the fees levied on wastes discharge at the province level, respectively.

All the related data were collected from China Statistical Yearbook, China Energy Statistics Yearbook, China Environmental Statistics Yearbook and China Power Statistical Yearbook.

\section{Results and Discussion}

\section{Spatiotemporal Characteristics}

Figs 1 and 2 depict the spatiotemporal characteristics of CE from China's power sector in terms of time and space dimension, respectively. As shown in Fig. 1, the CE from the power sector increased from 1.58 billion tons in 2003 to 3.88 billion tons in 2013, with an annual growth rate of $9.54 \%$. Regarding the ratio of $\mathrm{CE}$ from the power sector to the national level, it fluctuates frequently within the range of $40-50 \%$. The year 2011 witnessed the highest value. Due to the financial crisis that originated in the United States in 2008, China's economic growth slowed and electricity generation decreased, which lead to the power sector $\mathrm{CE}$ lowering slightly in subsequent years, and this trend has been changed since 2010. With the introduction of a national " 4 trillion investment," China's economy grew rapidly again and the demand for electricity also increased dramatically, which contributes to the increases both the total $\mathrm{CE}$ and the relative share of $\mathrm{CE}$. [26] This situation has changed with the introduction of the national $12^{\text {th }}$ Five-Year Plan. China's power industry enhanced the major pollutants governance and emission reduction work intensity, as well as implementing the project of replacing coal-fired power plants in big cities with gas-fired plants, thus the share of CE had a little decrease.

Fig. 2 summarized CE from the power sector in 2003, 2008, and 2013 from the perspective of the provincial level. It can be seen that there are big gaps among provinces. The provinces in the eastern area, such as Shandong, Jiangsu, Guangdong, and Hebei have the highest value of CE. In addition, provinces in the middle-western area, including Inner Mongolia, Shanxi, and Xinjiang, also witnessed large CE, which may be highly related to local energy resources. The primary energy resources used for electricity generation are not evenly distributed across the country, which resulted in large parts of electricity being transferred from

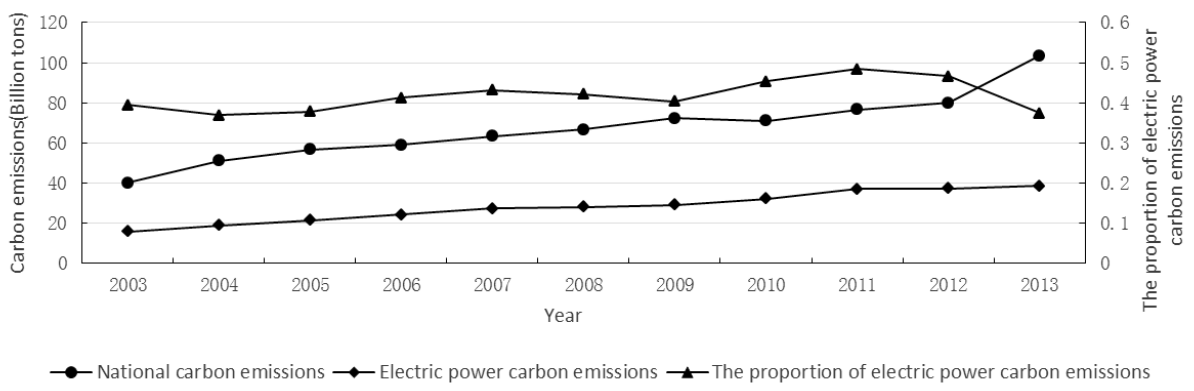

Fig. 1. Line chart of china's electric power CE (billion tons), 2003-2013.

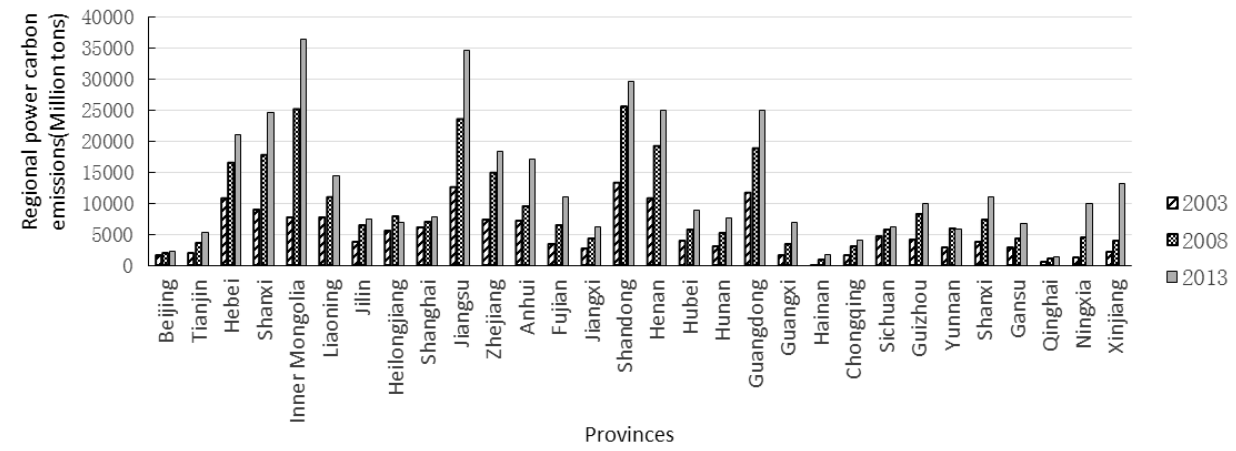

Fig. 2. Regional power CE (million tons) of 2003, 2008 and 2013. 
Table1. Global Moran's I Index of regional power CE performance and its significance.

\begin{tabular}{|c|c|c|c|c|c|c|c|c|c|c|c|}
\hline Year & 2003 & 2004 & 2005 & 2006 & 2007 & 2008 & 2009 & 2010 & 2011 & 2012 & 2013 \\
\hline Moran'I & 0.358 & 0.311 & 0.293 & 0.263 & 0.263 & 0.287 & 0.289 & 0.287 & 0.243 & 0.236 & 0.247 \\
\hline P-value & 0.002 & 0.004 & 0.007 & 0.012 & 0.011 & 0.007 & 0.007 & 0.007 & 0.014 & 0.017 & 0.014 \\
\hline
\end{tabular}

economically less developed provinces in the west to economic growth centers in the east, while leaving the pollution themselves.

\section{Spatial Autocorrelation}

We use Geoda095i software to measure the global Moran's I index of China's regional power CE in various periods from 2003 to 2013. It can be seen from Table 1 that the values of global Moran's I are positive and significant at the 5\% level in each period, which indicates that there is a strong spatial cluster in China's $\mathrm{CE}$ from the power sector. That is to say, provinces with similar CE tend to be concentrated geographically. Moreover, there is a remarkable fluctuation with the upward trend of global Moran's I index, as well as a fluctuation of its significance over time. Moran's I index dropped from 0.358 in 2003 to 0.263 in 2007, and increased to 0.289 in 2009 . Subsequently, it went down to 0.236 in 2012, and finally slightly rebounded to 0.247 in 2013 . That is to say, the spatial correlation of $\mathrm{CE}$ in China's regional power industry presents a constantly changing trend. So, the governments should strengthen the communication and cooperation among different regions in order to achieve common $\mathrm{CE}$ reduction.

In order to further test the spatial dependence and gain deeper insight into the cluster pattern of power CE in space, we draw the LISA maps of 2003 and 2013 to visually demonstrate the clustering types. As shown in Fig. 3, from 2003 onwards, except for a few provinces showing a distribution of LH clustering, most provinces have significantly positive spatial correlation $(\mathrm{HH}$ or LL) in the geospatial, and the significance maintains stability primarily and then continuously extends.
Moreover, H-H agglomerations in eastern central China have been continuously reduced and then increased in varying degrees. The majority of LL agglomeration is concentrated in the western region: Xinjiang, Qinghai, Sichuan and Yunnan. Overall, a clear east and west blocked spatial structure is existed. In other words, there is an imbalance in the spatial distribution of $\mathrm{CE}$ from the power sector.

\section{Results of the Spatial Dubin Model}

According to Table 2, the LMlag and LMerror test statistics of the non-space hybrid panel model are 8.534 and 23.103, respectively, both of which passed $1 \%$ significance level, indicating that the non-spatial is rejected in favor of SAR and/or SEM. Besides, both of the LM test and the robust LM test passed $1 \%$ and $5 \%$ significance tests under the scenario of considering the space-fixed effect, which cannot reject the null hypothesis without a space-lagged explanatory variable and the null hypothesis without space autocorrelation error term, meaning that the space fixed effect model should be used. However, the (robust) LM test under spatial fixed effects supports adopting SAR or SEM, so we further conduct Wald and LR tests to judge whether SDM can be simplified to SAR or SEM. As shown in Table 3, both the null hypothesis $H_{0}^{1}: \theta=0$ and $H_{0}^{1}: \theta+\delta \beta=0$ are rejected at $1 \%$ significance level. The results indicate that SDM cannot be simplified to SAR or SEM. Thus, the SDM with fixed effect was selected to analyze the determinants of China's provincial power CE.

Table 3 shows that the direct effect of UR is significantly positive at 5\% significance level, consistent with the expected sign. At present, China is in the
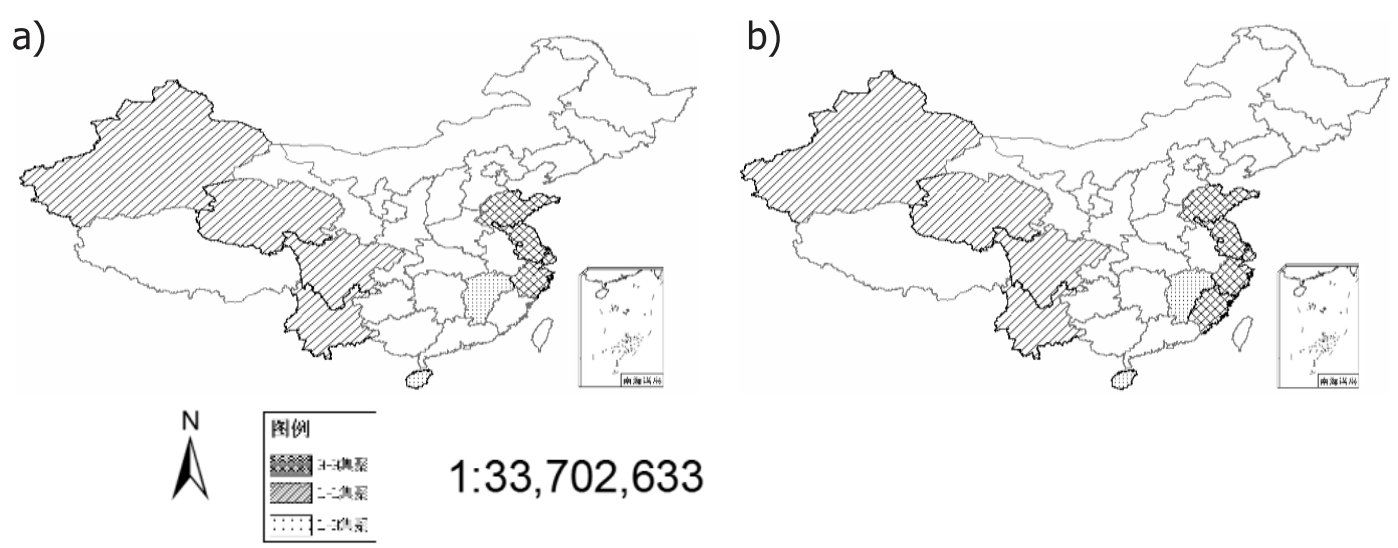

Fig. 3. LISA clustering maps of China's provincial power CE: a) 2003, b) 2013. 
Table 2. Estimation results of traditional pooled panel data model.

\begin{tabular}{|c|c|c|c|c|}
\hline Variables & No- fixed effects & Space- fixed effects & Time-fixed effects & $\begin{array}{l}\text { Space-and-time-fixed } \\
\text { effects }\end{array}$ \\
\hline UR & $\begin{array}{c}-0.007937 * * * \\
(-0.001188)\end{array}$ & $\begin{array}{c}0.648355 * * * \\
(4.844782)\end{array}$ & $\begin{array}{c}-0.761345 * * * \\
(-4.099934)\end{array}$ & $\begin{array}{c}0.385264 * * * \\
(2.883080)\end{array}$ \\
\hline P-GDP & $\begin{array}{c}0.419527 \\
(0.297216)\end{array}$ & $\begin{array}{l}-2.917289^{*} \\
(-1.680285) \\
\end{array}$ & $\begin{array}{c}0.064598 \\
(0.045264)\end{array}$ & $\begin{array}{l}-2.968675^{*} \\
(-1.764575) \\
\end{array}$ \\
\hline $\mathrm{P}-\mathrm{GDP} \wedge 2$ & $\begin{array}{c}-0.011871 \\
(-0.162859)\end{array}$ & $\begin{array}{l}0.181734 * \\
(1.911426)\end{array}$ & $\begin{array}{c}0.011972 \\
(0.161434)\end{array}$ & $\begin{array}{l}0.182868^{* *} \\
(1.972653)\end{array}$ \\
\hline ES & $\begin{array}{c}0.437998 * * * \\
(7.132817)\end{array}$ & $\begin{array}{c}0.657029 * * * \\
(7.045921)\end{array}$ & $\begin{array}{c}0.467097 * * * \\
(7.299704)\end{array}$ & $\begin{array}{c}0.579254 * * * \\
(6.423792) \\
\end{array}$ \\
\hline $\mathrm{MH}$ & $\begin{array}{l}-0.222168 \\
(-0.735110)\end{array}$ & $\begin{array}{l}-0.265843 \\
(-1.220342)\end{array}$ & $\begin{array}{c}0.099545 \\
(0.268445)\end{array}$ & $\begin{array}{c}0.675153 * * * \\
(2.668013)\end{array}$ \\
\hline EVIN & $\begin{array}{c}0.200298 * * * \\
(4.781951)\end{array}$ & $\begin{array}{c}0.156779 * * * \\
(6.074599)\end{array}$ & $\begin{array}{c}0.145237 * * * \\
(3.109765)\end{array}$ & $\begin{array}{c}0.085000 * * * \\
(2.946172)\end{array}$ \\
\hline FEE & $\begin{array}{c}0.567226^{* * * *} \\
(16.849949) \\
\end{array}$ & $\begin{array}{c}0.227789 * * * \\
(8.274924) \\
\end{array}$ & $\begin{array}{c}0.592482 * * * \\
(16.839840) \\
\end{array}$ & $\begin{array}{c}0.173650 * * * \\
(5.687189) \\
\end{array}$ \\
\hline $\mathrm{R}^{2}$ & 0.934 & 0.815 & 0.937 & 0.446 \\
\hline loglikols & 19.89 & 183.644 & 43.965 & 211.025 \\
\hline LMlag & $8.535^{* * *}$ & $20.554 * * *$ & $3.933^{*}$ & 0.045 \\
\hline R-LMlag & 1.081 & $17.636^{* * *}$ & 2.609 & 0.251 \\
\hline LMerror & $23.103^{* * *}$ & $6.833 * * *$ & 1.862 & 0.218 \\
\hline R-LMerror & $15.648^{* * *}$ & $3.915^{* *}$ & 0.537 & 0.424 \\
\hline
\end{tabular}

Note: ${ }^{* * *, * *, *}$ indicate $1 \%, 5 \%$ and $10 \%$ significance level, respectively

process of accelerated urbanization. [27] The growth of urban population will inevitably lead to the increase of total electricity consumption. At the same time, the improvement of urbanization will also promote the development of secondary and tertiary industries, which requires a large amount of electricity support, invisibly increasing power CE. Therefore, we will focus on industrial restructuring while continuing to upgrade the urbanization level, expanding the scale of the tertiary and light industry in order to achieve the goal of CE reduction.

The direct effects of the $\mathrm{P}-\mathrm{GDP}$ and $\mathrm{P}-\mathrm{GDP}^{\wedge} 2$ are all significant at the $1 \%$ level, which means that an inverted "U" relationship between power sector CE and P-GDP is supported. [24] Faced with the challenge of both maintaining economic growth and reducing $\mathrm{CE}$ from the power sector, it is necessary to readjust the mode of economic development and strive to realize the decoupling between economic development and $\mathrm{CE}$ from power sector.

The direct effect of ES is positive at the $1 \%$ significance level and was the highest among all variables. Nowadays, the proportion of thermal powergenerating units in China is more than $70 \%$, and a considerable part of the units are small thermal power units with relatively low efficiency. A consistent reinforcement of restricted market access for new facilities as well as phasing-out inferior technologies in obsolete facilities is required. [28] Therefore, the small and medium power plants with poor efficiency and high emissions should be banned. At the same time, it is critical to enhance the ratio of renewable energy in order to strengthen environmental protection.

The direct effect of $\mathrm{MH}$ was positive at the $5 \%$ significant level. The lower the $\mathrm{MH}$, the higher the coal-burning efficiency, and the less carbon dioxide emitted by producing the same amount of electrical energy. Therefore, reducing the $\mathrm{MH}$ is the key to effectively reduce the power CE. Actually, the annual $\mathrm{MH}$ in China is continuously decreased. In addition, some advanced generation technologies, such as IGCC (integrated coal gasification combined cycle), NGCC (natural gas combined cycle), and CCS (carbon capture and storage) should be taken as long-term strategies for China to promote its CE reduction [29].

The direct effects of EVIN and FEE are significantly positive at the $1 \%$ level (although Porter hypothesis states that appropriate ER can motivate companies to carry out more innovative activities, which will be helpful for CE reduction). Empirically, a more complicated impact of ER on CE is found. In our estimation, the positive effects may be related to the direction of the environmental regulation. Nowadays, most of the sewage charges are mainly used in water pollution control, sewage disposal and sulfide dioxide emission reduction, with little effects on CE. Thus, adjusting the direction of environmental regulation and focusing more on greenhouse gases reduction is necessary. 
Table 3. Estimation and test results of the SDM.

\begin{tabular}{|c|c|c|c|c|c|c|}
\hline Variables & Coefficients & $\mathrm{t}$ value & Direct effects & $\mathrm{t}$ value & Indirect effects & $\mathrm{t}$ value \\
\hline UR & $0.299586^{* *}$ & 2.089009 & $0.335903^{* *}$ & 2.410786 & $1.029765^{* * *}$ & 3.991039 \\
\hline P-GDP & $5.329717 * * *$ & -2.860586 & $-5.045181 * * *$ & -2.831055 & $10.107060 * *$ & 2.704542 \\
\hline $\mathrm{P}-\mathrm{GDP}^{\wedge} 2$ & $-0.307333 * * *$ & 3.040571 & $0.290954 * * *$ & 3.003407 & $-0.571734 * * *$ & -2.819362 \\
\hline ES & $0.598650 * * *$ & 6.181575 & $0.605719 * * *$ & 6.336012 & 0.221793 & 1.092741 \\
\hline MH & $0.606324 * *$ & -2.446663 & $0.581401^{* *}$ & -2.393810 & 0.729276 & 1.413961 \\
\hline EVIN & $0.094040 * * *$ & 3.314060 & $0.093672 * * *$ & 3.375662 & 0.035542 & 0.766143 \\
\hline FEE & $0.199338^{* * *}$ & 6.914797 & $0.201867 * * *$ & 6.920450 & $0.094329 *$ & 1.856939 \\
\hline $\mathrm{W} * \mathrm{UR}$ & $0.885665^{* * *}$ & 3.721989 & \multicolumn{4}{|c|}{$\mathrm{R}^{2}=0.978$} \\
\hline W*P-GDP & $9.824386^{* * *}$ & 3.005495 & \multicolumn{4}{|c|}{ Corrected- $\mathrm{R}^{2}=0.834$} \\
\hline $\mathrm{W}^{*} \mathrm{P}-\mathrm{GDP} \wedge 2$ & $-0.556725 * * *$ & -3.135597 & \multicolumn{4}{|c|}{$\operatorname{sigma}^{\wedge} 2=0.019$} \\
\hline $\mathrm{W} * \mathrm{JG}$ & 0.126870 & 0.670242 & \multicolumn{4}{|c|}{ log-likelihood=203.634 } \\
\hline $\mathrm{W}^{*} \mathrm{MH}$ & $0.754725^{*}$ & 1.653114 & \multicolumn{4}{|c|}{ Wald test spatial lag $=20.286^{* * *}$} \\
\hline $\mathrm{W}^{*} \mathrm{EVIN}$ & 0.020051 & 0.463640 & \multicolumn{4}{|c|}{ LR test spatial lag $=21.232 * * *$} \\
\hline $\mathrm{W} * \mathrm{FEE}$ & 0.061496 & 1.191563 & \multicolumn{4}{|c|}{ Wald test spatial error $=29.563 * * *$} \\
\hline $\mathrm{W}^{*}$ dep.var. & $0.120975^{*}$ & 1.694028 & \multicolumn{4}{|c|}{ LR test spatial error $=33.639 * * *$} \\
\hline
\end{tabular}

Note: ${ }^{* * *, * *, *}$ indicate $1 \%, 5 \%$ and $10 \%$ significance level, respectively

The direct effect only reflects the impact of a change of variable $k$ in province $i$ on the $\mathrm{CE}$ of province $i$, while the spillover effect (indirect effect) is an indicator to examine the spatial interaction among the regions. It can be seen from Table 3 that the spillover effects of UR, P-GDP, P-GDP^2 and FEE are significant, indicating that the impact of UR, P-GDP, $\mathrm{P}-\mathrm{GDP}^{\wedge} 2$ and FEE in one province will transmit to other neighboring provinces and will have a significant effect on the power CE of neighboring provinces. The increase of UR reduces the space for urban accommodation, and some people immigrate to the surrounding provinces, leading to the improvement of urbanization in the surrounding provinces and the rise of the corresponding power CE. With the increase in P-GDP in province $i$, some of the funds and population in the neighboring provinces and regions will gather and move toward the central provinces. As a result, the cluster flow will reduce the population, economic investment and other necessary elements for the development of the economy in neighboring provinces, and cut down the demand for electrical energy and the CE from power sector. The improvement of FEE will increase the production costs of enterprises and force enterprises in central areas to shift production to areas with relatively low sewage charges in order to reduce production costs. The relocation of production plants has increased the demand for electricity in the neighboring provinces and indirectly increased the power $\mathrm{CE}$ in neighboring provinces.

The spillover effects of ES and $\mathrm{MH}$ are not significant. Under the condition of the power sector without full marketization, it is difficult for a new power technology to affect the surrounding regions through competition spillover, and the central provinces will also be unable to use technology spillovers to drive the neighboring provinces and regions to jointly achieve carbon emission reduction. Thus, it is necessary to accelerate the process of marketization of the power industry, and gradually open up the electricity market in an orderly manner. At the same time, it is imperative to do a good job in national macro-control and avoid market-oriented chaos such as malicious competition.

Although the variable of FEE has a positive spillover effect, the spillover effect of EVIN is insignificant. This reveals the complicated effects of regulation on $\mathrm{CE}$ from the power sector. Meanwhile, it also reflects that the EVIN is not enough to induce the spillover effects. Thus, strengthening the EVIN may be imperative in practice.

The direct effects of these explanatory variables are different from their coefficients because of the feedback effect (feedback effect $=$ elasticity coefficient - direct effect). The production of feedback effect is due to the fact that its effect on one province's electricity CE will pass to the neighboring provinces, which is then passed back to the former. The effect report of UR, P-GDP, P-GDP^2, ES, MH, EVIN and FEE are -0.036317, $10.374898,-0.598287,-0.007069,0.024923,0.000368$, -0.002529 , but the impact is very weak. This feedback effect respectively comes from the interaction of space lag $\left(\mathrm{W}^{*} \mathrm{UR}, \mathrm{W}^{*} \mathrm{P}-\mathrm{GDP}, \mathrm{W}^{*} \mathrm{P}-\mathrm{GDP}^{\wedge} 2, \mathrm{~W}^{*} \mathrm{ES}, \mathrm{W}^{*} \mathrm{MH}\right.$, $\left.\mathrm{W}^{*} \mathrm{EVIN}, \mathrm{W}^{*} \mathrm{FEE}\right)$ of seven factors and the spacelagged explained variable. 


\section{Conclusions and Implications}

Overall, the CE from China's power sector has been increasing during the period 2003-2013. Initially, it increases at a fixed rate then becomes sluggish, subsequently appearing as a sharp increase, and finally it tends to be stable. Furthermore, it shows significant spatial correlation and spatial agglomeration characteristics. The clustering characteristics can be depicted as "higher in the east and lower in the west." Relevant influencing factors have a significant direct impact on electricity CE, of which ES has the greatest impact. Regarding spillover effects, variables of UR, P-GDP and FEE have a significant effect on electrical power CE. These results can have several policy implications.

First, the Chinese government should speed up the marketization reform of the power sector, the transmission of electricity from the west to the east, the optimization of the $\mathrm{CE}$ policy under environmental regulations, and the formation of a regional complementary mechanism to reduce electricity demand pressure in a high-demand area. At the same time, there is a need to formulate a differential power $\mathrm{CE}$ reduction policy according to the actual situation of each province.

Second, optimizing the ES and increasing the proportion of non-fossil energy generation will play a decisive role in the power $\mathrm{CE}$ reduction: (1) It is necessary to build more thermal power units with a large capacity, high efficiency, low energy consumption and low pollution emissions, and gradually force small thermal power units out of the market. Meanwhile, the government should control the development speed of large units and avoid the repeated construction and overinvestment of thermal power plants in a certain area. (2) Reducing fossil energy consumption of thermal power units and improving energy efficiency will be an important emission reduction measure in the power sector. The government should increase investment in manpower and capital for thermal power generation technology, make China's thermal power generation technology a world-leading level, optimize the utilization rate of coal combustion, and reduce power CE. (3) The government should give full play to the geographical advantages and local unique resources advantages, develop hydroelectricity rationally, utilize nuclear electricity safely, utilize wind power electricity efficiently and increase the installed capacity of natural gas, so as to gradually increase the installed proportion of clean energy and control $\mathrm{CE}$ by reducing the use of coal.

Third, the spatial spillover effect of inter-regional power CE should be considered to effectively control the power $\mathrm{CE}$ through regional common reduction activities. The spatial spillover effect is mainly guided by the spatial lag of power $\mathrm{CE}$ and economic development level. Therefore, policymakers need to pay attention to the direct and indirect impacts of economic development, population structure and environmental regulation on electric $\mathrm{CE}$. Adhere to the strategy of sustainable economic development and promote economic growth mode change from extensive to intensive. Effectively changing the economic structure and population structure, and optimizing the policy of environmental regulation on electricity $\mathrm{CE}$ would be a win-win solution to the power CE reduction and economic growth.

\section{Conflict of Interest}

The authors have not declared any conflict of interest.

\section{References}

1. CHAE Y., HOPE C. Integrated assessment of $\mathrm{CO}_{2}$ and $\mathrm{SO}_{2}$ policies in North East Asia. Climate Policy. 3 (1), 57, 2003.

2. FAN W., SUN Y., ZHU T., Wen Y. Emissions of HC, CO, $\mathrm{NOx}, \mathrm{CO}_{2}$, and $\mathrm{SO}_{2}$ from civil aviation in China in 2010. Atmospheric Environment. 56, 52, 2012.

3. TIAN H., QIU P., CHENG K., GAO J., LU L., LIU K., LIU X. Current status and future trends of $\mathrm{SO}_{2}$ and $\mathrm{NOx}$ pollution during the 12th FYP period in Guiyang city of China. Atmospheric Environment. 69, 273, 2013.

4. ZHANG C., LIN Y. Panel estimation for urbanization, energy consumption and $\mathrm{CO}_{2}$ emissions: a regional analysis in China. Energy Policy. 49, 488, 2012.

5. WANG F., SHACKMAN J., LIU X. Carbon emission flow in the power industry and provincial $\mathrm{CO}_{2}$ emissions: Evidence from cross-provincial secondary energy trading in China. Journal of Cleaner Production. 159, 397, 2017.

6. CHEN Q.X., KANG C.Q., MING H., WANG Z.Y., XIA Q., XU, G. X. Assessing the low-carbon effects of interregional energy delivery in China's electricity sector. Renewable and Sustainable Energy Reviews. 32, 671, 2014.

7. PAUL S., BHATTACHARYA R. $\mathrm{CO}_{2}$ emissions from energy use in India: a decomposition analysis. Energy Policy. 32, 585, 2004.

8. ANG B.W., ZHANG F, CHOI K.H. Factorizing changes in energy and environmental indicators through decomposition. Energy. 23, 489, 1998.

9. ANG B.W. Decomposition analysis for policymaking in energy: which is the preferred method? Energy Policy. 32, 1131, 2004.

10. MALLA S. $\mathrm{CO}_{2}$ emissions from electricity generation in seven Asia-Pacific and North American countries: A decomposition analysis. Energy Policy. 37, 1, 2009.

11. ANG B.W., SU B. Carbon emission intensity in electricity production: A global analysis. Energy Policy. 94, 56, 2016.

12. ZHANG M., LIU X., WANG W., ZHOU M. Decomposition analysis of $\mathrm{CO}_{2}$ emissions from electricity generation in China. Energy Policy. 52,159, 2013.

13. LI H.N., MU H.L., ZHANG M., LI N. Analysis on influence factors of China's $\mathrm{CO}_{2}$ emissions based on Path-STIRPAT model. Energy Policy. 39, 6906, 2011.

14. YAN H., GUO Y.G., LIN F.C. Analysis of Shanghai Urban Development Model under $\mathrm{CO}_{2}$ Control Based on STIRPAT Model. Acta Geographica Sinica. 65, 983, 2010.

15. ZHU Q., PENG X.Z., LU Z.M. Analysis model and demonstration of the impact of population and consumption 
on carbon emissions. China Population Resources and Environment. 20, 98, 2010.

16. LONG R.Y., SHAO T.X., CHEN H. Spatial econometric analysis of China's province-level industrial carbon productivity and its influencing factors. Applied Energy. 166, 210, 2016.

17. TOBLER W. A computer movie simulating urban growth in the Detroit region. Economic Geography. 46, 234, 1970.

18. LESAGE J.P. What Regional Scientists Need to Know About Spatial Econometrics. Social Science Electronic Publishing. 44 (1), 13, 2014.

19. IPCC. Greenhouse Gas Inventory: IPCC Guidelines for National Greenhouse Gas Inventories. United Kingdom Meteorological Office. Bracknell, England. 1995

20. FAN Y., LIU L.C., WU G., WEI Y.M. Analyzing impact factors of $\mathrm{CO}_{2}$ emissions using the STIRPAT model. Environmental Impact Assessment Review. 26 (4), 377, 2006.

21. LI H.N., MU H.L., ZHANG M., LI N. Analysis on influence factors of China's $\mathrm{CO}_{2}$ emissions based on Path-STIRPAT model. Energy Policy. 39 (11), 6906, 2011.

22. SHRESTHA R.M., ANANDARAJAH G., LIYANAGE M.H. Factors affecting $\mathrm{CO}_{2}$ emission from the power sector of selected countries in Asia and the Pacific. Energy Policy. 37, 2375, 2009.
23. HOLTZ-EAKIN D., SELDEN T.M. Stoking the fires? $\mathrm{CO}_{2}$ emissions and economic growth. Journal of Public Economics. 57, 85, 1995.

24. YANG L. and LIN B. Carbon dioxide-emission in China's power industry: Evidence and policy implications. Renewable and Sustainable Energy Reviews. 60, 258, 2016.

25. ZHAO X., YIN H., ZHAO Y. Impact of environmental regulations on the efficiency and $\mathrm{CO}_{2}$ emissions of power plants in China. Applied Energy. 149, 238, 2015.

26. ZHOU S.L., SHI M.J., LI N., YUAN Y.N. Effects of Chinese Economic Stimulus Package on Economic Growth in the Post-Crisis China. Economics Research International. 2011.

27. HAN L., GUO J., LIU Z. International Comparison and Inspiration on Urbanization: Understanding of the Present Stage of Urbanization in China. Urban Development Studies. 2014.

28. LIU X.Y., WEN Z.G. Best available techniques and pollution control: a case study on China's thermal power industry. Journal of Cleaner Production. 23, 113, 2012.

29. WANG X.P., DU L. Carbon emission performance of China's power industry: Regional disparity and spatial analysis. Journal of Industrial Ecology. 21 (5), 1323, 2017. 